\title{
The relationship between Gender Mainstreaming approaches and the Performance of Rice growers' cooperative in Bugesera District, Rwanda
}

\author{
Amara M. Kamara ${ }^{1}$ and Ernest Safari ${ }^{2}$ \\ ${ }^{1}$ School of Social Sciences, Mount Kenya University, \\ Kigali, Rwanda \\ ${ }^{2}$ School of Social Sciences, Mount Kenya University, \\ Kigali, Rwanda
}

\begin{abstract}
To assess the correlation between Gender mainstreaming approaches (gender incorporate prospectus, sex-disaggregated data, and gender budgeting) and the performance of Rice growers' cooperative in Bugesera District, Rwanda. This study is an important tool for government, society, and the researcher by formulating Gender mainstreaming strategies to improve the state of development projects in the country. The descriptive and analytical research was adopted. The sample size of the study is 83 respondents drawn from the selected registered cooperative's members in Bugesera District, Rwanda, and was determined by using Sloven's formula. Data collection instruments were both primary and secondary which include questionnaires; interview guide and documentary review and a purposive sampling technique was used. Data was analyzed using computer software called Statistical Package for Social Scientists (SPSS) version 22. Quantitative data was analyzed using descriptive statistics, Chi-square, and multivariate analysis using SPSS v22 while qualitative data was analyzed thematically. Concerning the major findings related to the research question one, the study revealed that there is a positive relationship between Gender Mainstreaming approaches and Success factors of Rice growers' Cooperative as it was confirmed by the Pearson correlation(r) $=0.787^{* *}$. This means that there is a high positive correlation between the two variables.
\end{abstract}

Keywords:

Mainstreaming, gender mainstreaming, development, cooperative, sustainable development and gender equality

\section{Introduction}

Globally, the success and sustainability of any development project or priority are determined by a range of factors, including the participation and contribution of both genders. It is in this regard that different development partners in their programs and projects, especially in the developing countries, have acknowledged gender mainstreaming as a severe problem that deserves immediate attention and to create working solutions to subsequent problems therein (Grigorian, 2007). According to the UN Women (2013), one of the major strategies to address this problem, national and international cooperative such as the United Nations, World Bank, and the European Union, and others have advanced "gender mainstreaming" as a strategy for making women as well as men's concerns and experiences an integral dimension. This includes the design, implementation, monitoring, and evaluation of policies and programs in all political, economic, and social spheres. Women and men benefit equally, and inequality is not perpetrated in all development programs as it has been practiced for years.

Rwanda adopted the Beijing Platform for Action and undertook strategic actions aimed at tackling challenges that impede the progress of development. It has ratified and adhered to many international and regional conventions, charters, and declarations, including, the CEDAW, the Millennium Development Goals (MDGs), the United Nations Security Council Resolution 1325, the Universal Declaration of Human Rights of 10 December 1948, the New Partnership for Africa's Development(NEPAD), Southern African 
Development Community (SADC), COMESA and among others. All these instruments highlight gender as an important approach for sustainable development (GMO, 2011).

According to the National Institute of Statistics of Rwanda, (2006), the government has formulated the Rural Sector Support Program as one of the many projects that the country is using to achieve both growth and poverty alleviation. The program is primarily engaged with support to registered NGOs and cooperatives in the country. Rice growers' cooperative in Bugesera District is one of the beneficiaries of the program as part of efforts to increase support towards rural development.

Despite all the initiatives over time to address issues of gender inequality, declaration of human rights, and the celebration of the women's year in 1975, the different world conferences on women (Mexico city conference, Beijing conference, Nairobi conference, etc.) and even the current millennium development goals, significant disparities persist and a lot remain to be done to bridge gender gaps including women's poor conditions and related socioeconomic inequality, such as witnessed in Rwanda, as such it's clear that, the success of development project is strongly affected, (O'Brien, 2011). Overall, many cooperatives mainly work on gender mainstreaming, and several cooperatives work on promoting the rights of persons, women, and vulnerable men. To be able to address the above challenges, this study focused on gender mainstreaming on the performance of Rice growers' cooperative in the Bugesera District, Rwanda.

\section{Review of Literature}

According to Kirimi (2012), to be transformative, the commitment to gender equality should be universal; address the structure of gender-based inequality, including in the three dimensions of sustainable development social, economic, and environmental; and ensure accountability. The author further adds that building on the experiences and lessons learned from the MDGs. Gender equality thus needs to be addressed both as a stand-alone goal and as an issue cutting across all other parts of the agenda, to address gender-based discrimination specific to each development sector and to ensure the meaningful achievement of all other goals (Seniloli, et al., 2016).

As noted by Head et al., (2014), disaggregating data by other vital characteristics along with sex, like geographic location, enables researchers to take account of the interplay between gender and other individual and structural factors. The rationale of both gender analysis and sex-disaggregated data is that it helps systemically mainstream development priorities where women will feel significantly part of development activities (Kusakabe, 2005).

In the context of gender prospectus and strategy, equality ensures more of the macro level of how development priorities benefit men and women without leaving anyone behind. Women should be at the hierarchies of development priorities like men, and development frameworks and priorities must be strictly gendered sensitive (Baden, 2009).

Meanwhile, Ford \& Parker (2008) argue that the quantitative aspect of achieving gender equality and ensuring the success of development refers to the desire to achieve equitable representation of women, increasing balance and parity. The authors further add that the qualitative aspect refers to achieving real influence on establishing development priorities and outcomes for women and men without compromising the preferences of any of the gender. Equality involves ensuring that the perceptions, interests, needs, and importance of women and men are given equal weight in planning and decisionmaking and are treated equally. Building on the experiences and lessons learned from the MDGs, gender equality needs to be addressed both as a stand-alone goal and as an issue cutting across all other parts of the development agenda that would address the challenges faced by both women and men with greater emphasis on the priorities of women (Sraboni et al., 2014).

According to Jones, et al. (2010), women have critical roles in creating social and economic development for their households. However, although women make substantial contributions to household well-being, the inability to value their work reduces women to virtual non-entities in monetary transactions, the allocation of household resources, and a wide range of decision-making. Much as the Daly (2009) studies show that there is growing interest in supporting development projects to enable the vulnerable female to secure sustainable livelihoods.

Although Mogues et al., (2013) note that some gender gaps have narrowed, such as by increasing the numbers of female agricultural extension workers and developing women-specific support packages, new land certification policies favoring joint ownership as indicated by Kumar \& Baden (2009) and increased investment in women and girl education as noted however, not enough is being done to help women access resources, services, and capacity building opportunities needed to equitably participate in farming projects. Women still face 
periodic discrimination as relates to accessing public resources as well as the household levels. Most like the agriculture sector are being used to mainstream women's priorities as men (Chayal et al., 2010).

Meanwhile, researchers have not adequately tackled the barriers of gender mainstreaming to the success of development projects. They are yet to establish the factors that influence gender mainstreaming and the success of development projects and establish the correlation between gender mainstreaming and development projects. There have been several studies done that primarily considered the political aspect of gender mainstreaming and the equal participation of both men and women in decision making and leadership - the socioeconomic characteristics of mainstreaming lack if not researched. The researcher uses these theories as they integrate all the necessary elements required for effective gender mainstreaming. The approaches are vital for the study's theoretical framework to outline and analyze the expected results as pertains to gender mainstreaming, and the models have been selected as they outline a better framework for investigating factors that affect gender mainstreaming in NonGovernmental cooperative. Through these appropriate gender mainstreaming mechanisms and policies, both men and women are the stakeholders of development projects, like in the case of the success of development projects in Rwanda. Therefore, it is in this regard that the study was conducted to assess the influence of gender mainstreaming and the success factors of Rice growers' cooperative in Bugesera District, Rwanda.

\section{Materials and Methods}

The researcher adopted a descriptive research design. These methods were used because descriptive design helps to systematically ascertain and describe the characteristics of the variables. The evaluative research design helped establish the Gender mainstreaming approaches such as Gender incorporate prospectus, Gender budgeting and Sexdisaggregate data and the performance of Rice growers' cooperative in Bugesera District. Kothari (2014) defines descriptive research studies as those concerned with describing the characteristics of a particular individual or a group. The study was carried out within Rice Growers Cooperative, which consisted of respondents selected from 491 registered members of Rice-growers' cooperative and the key informants in such as 18 RSSP staff in Bugesera District. The study involved project registered members and CDF staff with a target population of 509 respondents.

The researcher has used of Sloven's Formula as indicated.

$$
n=\frac{N}{1+N a^{2}}
$$

Where

$$
\begin{aligned}
\mathrm{n} & =\text { number of samples } \\
\mathrm{N} & =\text { total population } \\
\mathrm{a} & =\text { level of significance } 0.10
\end{aligned}
$$

Sample size: $\quad=\frac{509}{1+\left(509 X(0.10)^{2}\right)}$

$$
\begin{aligned}
& \frac{509}{6.09} \\
= & 6.09 \\
= & 83
\end{aligned}
$$

Table 3.1: Categories of respondents

\begin{tabular}{lllll}
\hline \multicolumn{1}{c}{ Respondents } & Population & Percentage & Sample size & Percentage \\
$(\%)$ & $(\%)$ & & \\
& & & & 10.9 \\
RSSP staff & 18 & 3.5 & 9 & 89.1 \\
Community Members & 491 & 96.5 & 74 & 100 \\
Total & 509 & 100.0 & 83 & \\
& & & &
\end{tabular}

Source: Researcher own design (2020) 
To get the sample for quantitative data, a simple random sampling method, which refers to a subset of individuals (a sample) chosen from a more extensive set (a population), was used to select the respondents. This method was used because every registered member had an equal chance of inclusion in the sample, and each one of the possible members had the same probability of being selected.

For qualitative data, the RSSP staff were selected using purposive sampling. Purposive sampling is acceptable for special situations. It uses the judgmental selection of cases when a difficult-toreach population needs to be measured or when the targeted instances are few and far. The targeted respondents are specific because of possession of particular characteristics, which is the situation for managers and administrations in the selected cooperative. A non-representative subset of some larger population is constructed to serve a specific need or purpose. These are information-rich cases that facilitated in-depth interviews. The sample size of 9 RSSP staff was considered as key informants.

\section{Results and Discussion}

\subsection{Demographic Characteristics of Respondents}

This method was used because the results are expected to be more accurate.

The questionnaire was the favored tool of my research as it provided a cheap and effective way of collecting data in a structured and manageable form, which was written in a simple language and collected the detailed information required. This method was applied in collecting data from RSSP project registered members. The questionnaire was structured and had closed questions. To ease the processing of data, options for answers were provided where applicable. Data was collected from both forms of primary and secondary sources. Secondary data was collected through desk studies and publications. Closed-ended questions were used to ensure that the given answers are relevant. The questions were developed based on information and experiences gathered from the cooperative. For the Interview Guide, Selected RSSP staff were asked questions to determine their perceptions about gender mainstreaming and the success factors of Rice growers' cooperative

Table 4.1: Gender of Respondents

\begin{tabular}{|c|c|c|}
\hline & Frequency & Valid Percent \\
\hline Male & 47 & 55.3 \\
\hline Female & 38 & 44.7 \\
\hline Total & 85 & 100.0 \\
\hline
\end{tabular}

Source: Primary Data (2020)

From Table 4.1, the majority of respondents are males $(55.3 \%)$, while females are $44.7 \%$. Women's involvement in cooperatives in Rwanda is low compared to the number of males. This has been influenced by cultural factors that did not allow women to participate in cooperative membership and run a business without the permission of husbands. Instead, they had to stay at home to reproduce and raise children. This helps explain why their involvement is still low, but the government encourages women to be more active in different sectors of the economy.

\section{Table 4.2: Level of Educational}

\begin{tabular}{lll}
\hline & Frequency & Percent \\
Never attended school & 4 & $4.70 \%$ \\
Primary & 43 & 50.58 \\
Secondary school & 25 & 29.41 \\
\hline
\end{tabular}




\begin{tabular}{lll}
\hline Tertiary/College & 13 & 15.29 \\
Total & 85 & 100.0 \\
\hline
\end{tabular}

Source: Primary Data (2020)

According to the data collected in Table 4.2, 95.30\% of respondents can read and write, while $4.70 \%$ remain illiterate. This indicates that most of the respondents have the potential to influence decision making because they have some level of education. However, their overall educational level is insufficient to stimulate innovation or boost business plan development for the cooperative. Therefore an innovative approach is required to enable the progress of the Rice growers' cooperative with emphasis on women.

Table 4.3: Ages of respondents

Frequency Valid Percent

Below 25 years

25-30 years

31-40years

$41-50$

Above 50years

Total
16

12

32

14

11

85
14.1

18.8

37.6

16.5

100.0

\section{Source: Primary Data (2020)}

The results in Table 4.3 mean that the majority of respondents were between 31-40 years old, which represented $37.6 \%$ of respondents, between 25-30 years old represent $18.8 \%$ of respondents, between 41-50 years represent $16.5 \%$ of respondents, below 25 years which represented by $14.1 \%$ and above 50 years represent $12.9 \%$ of respondents. This means that the majority of the members are adults and family heads who can contribute a lot to the success of the cooperative giving that the required skills are obtained.

Table 4.4: Working experience in Rice growers' cooperative

\begin{tabular}{lll}
\hline & Frequency & Valid Percent \\
& & \\
Less than 1year & 8 & 9.4 \\
& & 34.1 \\
1-3years & 29 & 27.1 \\
4-6years & 23 & 16.5 \\
7-9years & 14 & 12.9 \\
9years and above & 11 & 100.0 \\
Total & 85 & \\
\hline
\end{tabular}

Source: Primary Data (2020) 
The results in Table 4.4 mean that the majority of respondents were between 1-3 years old, which represented by $34.1 \%$ of respondents, between 4-6 years old represent $27.1 \%$ of respondents, between 7 -

Table 4.5: Correlation between Gender Mainstreaming Approaches and Performance of Rice growers' Cooperative"
9 years represent $16.5 \%$ of respondents, below 1 year which represented by $9.4 \%$ and above 9 years represent $12.9 \%$ of respondents.

Performance_on Rice

Gender Mainstreaming growers' Cooperative

Approaches

\begin{tabular}{|c|c|c|c|}
\hline Gender_Mainstreaming & Pearson Correlation & 1 & $.787^{* *}$ \\
\hline Approaches such as gender & Sig. (2-tailed) & & .000 \\
\hline and gender incorporate prospectus & $\mathrm{N}$ & 85 & 85 \\
\hline Performance on the Rice growers' & Pearson Correlation & $.787^{* *}$ & 1 \\
\hline \multirow[t]{2}{*}{ Cooperative } & Sig. (2-tailed) & .000 & \\
\hline & $\mathrm{N}$ & 85 & 85 \\
\hline
\end{tabular}

**. Correlation is significant at the 0.01 level (2-tailed).

\begin{tabular}{|c|c|c|}
\hline 1 & $r=1$ & Perfect correlation \\
\hline 2 & $0.9 \leq r<1$ & A strong correlation (very high ) \\
\hline 3 & $0.6 \leq r<0.9$ & High correlation \\
\hline 4 & $0.5 \leq r<0.6$ & Moderate correlation \\
\hline 5 & $r<0.5$ & Weak(low) correlation \\
\hline 6 & $r=0$ & Absence of correlation \\
\hline
\end{tabular}

Source: Aggresti\& Franklin (2009)

Table 4.5 shows a high correlation between Gender Mainstreaming approaches (Sex Disaggregated Data \& Gender analysis, Gender Budgeting, Gender Incorporate Prospectus) and Success Factors of Ricegrowers' Cooperative (Increasing awareness, Sustainability, Lasting outcomes to the beneficiaries). The Pearson correlation $(r)=0.787^{* *}$. This means that there is a high correlation, and it can influence the success and progress of the cooperative. In short, efforts to mainstream gender in all activities have a strong relationship with the performance of the Rice growers' cooperative in Bugesera District, Rwanda. Also, the finding shows a positive relation between gender mainstreaming and the outcomes of development projects, knowing that in order to alleviate poverty, both genders ( men and women) should be captured at all stages of development activities by being gender sensitive during budgetary allocation and the implementation of development projects.

\subsection{Discussion}

This study was conducted to determine the gender mainstreaming approaches and performance of Rice growers' cooperative in Bugesera District, Rwanda. In this study, Literature agrees with the findings of Cunningham (2015), for effective gender mainstreaming, and the success of development activities, the budgets of development activities must involve gender perspectives at all levels. When gender-responsive budgeting is fully adhered to and facilitates the effective implementation of gender equality policies, the gap between women and men will be closed. It will lead to addressing the priorities of both genders. 
According to Table 4.5, the study finds that there is a high correlation between Gender Mainstreaming approaches (Sex Disaggregated Data \&Gender analysis, Gender Budgeting, Gender Incorporate Prospectus) and Performance of Rice growers' Cooperative (Increasing awareness, Sustainability, Lasting outcomes to the beneficiaries). The Pearson correlation $(r)=0.787 * *$.This means that there is a high correlation between the two variables. Therefore, Gender mainstreaming can lead to the performance of the Rice growers' cooperative in Bugesera District, Rwanda.

Respondent: Due to limited skills acquired by women, we have experienced low participation of women relative to our project activities. We are however engaging our partners like the Rural Sector Support Program to direct efforts to training mainly women on basic project management skills. By doing this we can ensure broader participation of both genders.

\section{Conclusions}

The main focus of this research project was to determine Gender Mainstreaming approaches and Performance of Rice growers' cooperatives in the Bugesera District.

Concerning the significant findings related to research question one, the study revealed that most respondents agreed that Gender Mainstreaming approaches include Sex Disaggregated Data \&Gender analysis, Gender Budgeting, Gender Incorporate Prospectus influence the performance of Rice growers' cooperative in Bugesera District.

In line with research question two, most respondents agreed on the success factors of rice growers' Cooperatives that include Increasing awareness, Sustainability, and lasting outcomes to the beneficiaries. The study revealed that there is a high correlation between Gender Mainstreaming approaches (Sex Disaggregated Data \&Gender analysis, Gender Budgeting, Gender Incorporate Prospectus) and Performance of Rice growers' Cooperative (Increasing awareness, Sustainability, Lasting outcomes to the beneficiaries) as it was confirmed by the Pearson correlation $(r)=0.787 * *$. This means that there is a high correlation between the two variables.

\section{Acknowledgments}

I wish to acknowledge Dr. Ernest Safari (PhD) for his contribution to this work from the beginning up to it's the completion. I need to extend my acknowledgement to the Mount Kenya University,
Bugesera District authorities for their support and collaborative in term of data collection

\section{Reference}

[1] Amnesty International. (2010). Insecurity and Indignity, Women's experiences in the slums of Nairobi, Kenya. London, United Kingdom: Amnesty International Publications

[2] Baden, S. (2009). "Practical Strategies for Involving Women as Well as Men in Water and Sanitation Activities, Bridge Report 11(9), 6-8

[3] Blair, A., \&amp; Abedi, M. (2015).Rural women participation in extension activities Journal of Agriculture Sciences.

[4] Blackburn K\&Wakai, S. (2004).Empowering rural women through a community development approach in Nepal. Kantipur, Nepal: Community Development, 5(2), 20-27

[5] Cunningham, K., \&amp; Ferguson, E. (2015).Women's empowerment in agriculture and child nutritional status in rural Nepal Public Health.Kantipur, Nepal: Community Development, 15(3),35-50

[6] Chayal, K.L, Seniloli, M, L.(2012). “Gender Issues in Environmental Sustainability and Poverty Reduction in the Community-Social and Community Issues," Development Bulletin, no. 58

[7] Daly, Mary E. (2005).Gender mainstreaming in theory and practice: Oxford University: Social politics international studies in gender, state, and society, 12(3), 433-450.

[8] Debusscher\& Doss, C., Deere, D., \&amp; Oduro, H. (2012).The Gender Asset and Wealth Gaps, Evidence from Ecuador, Ghana, and Karnataka. India (Bangalore): Indian Institute of Management Bangalore.

[9] Ford, B., (2008). The role of women in agriculture. Agricultural Development Economics Division the Food and Agriculture Cooperative of the United Nations www.fao.org/economic/esa: ESA Working Paper No. 11-02

[10] Government of Uganda, (2003).Water Sector Gender Strategy. Kampala, Uganda: Environment. Directorate of Water Development,Government of UgandaGlobal Gender Gap, p.20.http://www.weforum.org/issues/globalgender-gap (accessed April 3, 2013).

[11] Gender Monitoring Office (2011).Assessment of gender-related international and regional instruments and their implementation in the Republic of Rwandahttp://gmo.gov.rw

[12] GOP-NEDA .(2011). Philippine Development Plan 2011-2016. Government of the Philippines: National Economic Development Authority. 
[13] Grigorian, H. (2007). Impact of Gender Mainstreaming in Rural Development and Millennium Development Goals (MDGs). UNDP Gender Mainstreaming Annual Conference, 826

[14] Republic of Rwanda. (2009). National Evaluation of the implementation of the BeijingDeclaration and Platform for Action (1995) And The Outcome of the Twenty- Third Special Session of the General Assembly (2000). September 2009. Kigali.

[15] Sören\& Ericsson.(2008). "Sustainable work systems and complexity: a social challenge." Science for sustainable development. VHU, Uppsala:The social challenge with emphasis on the conditions for change. Proceedings of the 2nd VHU conference for sustainable development

[16] Stotsky C., \&amp; Porter, F. (2006).Mainstreaming Gender in Development. Oxford, UK: Oxfam Publication

[17] Sraboni, E., \&amp; Ahmed, A. U. (2014).Women's empowerment in agriculture: What role for food security in Bangladesh. Bangladesh: world development Journal, 61(2), 11-52.

[18] United Nations Division for the Advancement of Women.(2005).Women 2000 and Beyond: Women and Water.

[19] UN Women. (2013).A Transformative StandAlone Goal on Achieving Gender Equality Women's Rights and Women's Empowerment.In the context of the Post-2015 Development Framework and Sustainable Development Goals.

[20] Kirima, L. K. (2012). Contextual Factors Affecting Gendzr Mainstreaming in the Public Sector. Kenya: Ministry of Education, Eastern Province. (Kenyatta University), 45-52

[21] Kusakabe, R \&Manuh, T. (2005). Women in Africa's Development: Overcoming obstacles, pushing for progress. United Nations Department of Public Information: Africa Recovery Briefing Paper Issue 11

[22] Langer, L. \& Maguire, R. (2015).Bottom-Up Development in Haiti.Rosslyn, VA: InterAmerican Foundation

[23]Lee, S.-H. (2016). Gender mainstreaming in South Korea - a critical analysis through discursive institutionalism around the issue of childcare. Diplomacy and International Relations conference proceedings., 4-8

[24] Malapit, L., N Tyagi, P. (2015).Women's empowerment mitigates the negative effects of low 57 production diversity on maternal and child nutrition in Nepal. The Journal of Development Studies, 51(8), 1097-1123.

[25] March, C., Smyth, I. \&amp; Mukhopadhyay, M. (2008).A Guide to Gender. London: Oxfam GB Analysis Frameworks.

[26] Meinzen-Dick, A. (2001). Engendering Agricultural Research, IFPRI Research Monograph.Washington, DC: International Food Policy Research Institute. 